\title{
Causes of Death among HIV-Infected Adults Registered in Selected Anti-Retroviral Therapy Centers in North-Eastern India
}

\author{
Chiranjeev Bhattacharjya1, Damodar Sahu ${ }^{2 *}$, Sangram Kishor Patel ${ }^{3}$, Niranjan Saggurti³, \\ Arvind Pandey ${ }^{2}$ \\ ${ }^{1}$ Assam State AIDS Control Society, National AIDS Control Organization, Guwahati, India \\ ${ }^{2}$ National Institute of Medical Statistics, ICMR, New Delhi, India \\ ${ }^{3}$ HIV and AIDS Program, Population Council, New Delhi, India \\ Email: sahud@icmr.org.in
}

Received 9 April 2015; accepted 28 May 2015; published 3 June 2015

Copyright (C) 2015 by authors and Scientific Research Publishing Inc. This work is licensed under the Creative Commons Attribution International License (CC BY). http://creativecommons.org/licenses/by/4.0/

(c) (i) Open Access

\section{Abstract}

Background: Causes of death related studies in HIV infected population are necessary to devise disease specific preventive interventions at both state and national level HIV programs. This study examines the causes of death among HIV-infected individuals registered at selected Anti-Retroviral Therapy (ART) centers in the era of treatment in north-eastern India. Data and Methods: A retrospective chart review of causes of death was undertaken among HIV-infected patients who were treated between January 2006 and November 2012 at three selected ART centers in Assam, a north-eastern state of India. Reported causes of death were coded as per the guidelines of the International Classification of Diseases (ICD-10) to determine the deaths to standard definitions. Results: Among 5612 HIV-infected patients registered over a period of 71 months, 370 deaths have occurred. Tuberculosis (28\%) was the leading cause of death followed by death due to AIDS related complex (11\%), wasting syndrome and multiple infections (9\% each). Deaths due to selected causes were significantly associated with patient's use of alcohol, WHO clinical stage, CD4 count at the time of diagnosis, presence of opportunistic infections during treatment and ART adherence. Median survival duration was shortest among patients who had CD4 count $<50$ at the start of ART (2.9 months) and patients who had multiple opportunistic infections during treatment (2.5 months). Discussion: Majority (67\%) of deaths in our study were due to AIDS-related causes. Tuberculosis has remained the leading cause of death among the HIV patients on ART. Strengthening the linkages and referral between the HIV and TB program will be crucial to reduce the AIDS-related deaths attributed to tuberculosis.

\footnotetext{
${ }^{*}$ Corresponding author.
}

How to cite this paper: Bhattacharjya, C., Sahu, D., Patel, S.K., Saggurti, N. and Pandey, A. (2015) Causes of Death among HIV-Infected Adults Registered in Selected Anti-Retroviral Therapy Centers in North-Eastern India. World Journal of AIDS, 5, 90-99. http://dx.doi.org/10.4236/wja.2015.52011 


\section{Keywords}

\section{Causes of Death, HIV, AIDS, Tuberculosis, ART, Assam, Northeastern India}

\section{Introduction}

Causes of death related studies among HIV infected population are necessary to devise disease specific preventive interventions in HIV programs. Globally, increase use of antiretroviral therapy (ART) has decreased AIDSrelated deaths to a great extent [1]-[4]. With the inclusion of more effective and tolerable ART regimens, it is important to monitor causes of death and assess associated risk factors. The ART program in India was launched in 2004 and free services were being provided across 230 ART centers across the country [5]. As per National AIDS Control Organization (NACO), fewer AIDS-related deaths have been recorded in 2011 than a decade ago as a consequence of the extensive availability and access to antiretroviral therapy since 2006 in India [6]. A study from southern India reported the decrease in mortality from 25 to 5 deaths per 100 person years among HIV infected individuals between 1997 and 2003 after initiation of ART [7]. A retrospective study from Andhra Pradesh in India conducted over a 14-year period on 2050 HIV-infected patients reported more deaths in highly active antiretroviral therapies (HAART) era as compared to pre HAART era [8]. Although AIDS-related death rates have declined, the associated co-morbidities continue to gain increased attention from the national program. Other published studies from India suggest that HIV-infected individuals are at greater risk of acquiring selected opportunistic infections such as Tuberculosis, oral candidiasis, and other non-communicable diseases increasing their risk for death [9]-[12]. In Southern India reported about 37\% of the total deaths among HIV infected individuals were due to AIDS related causes, however, considerable $22 \%$ deaths also occurred deaths due to non-AIDS defining malignancies like lung cancer, anal cancer, liver cancer and Hodgkin Lymphoma, liver diseases and multiple organ failure [13] [14].

The search for literature around detailed descriptions of the causes of death among HIV-infected individuals pointed to few micro level studies in India [5] [7]-[9], and no studies found from the north-eastern India. More importantly, studies examining the factors associated with selected causes of death are limited in India. We therefore, examine the causes of death and related characteristics among HIV-infected individuals treatment at the ART centers in north-eastern India.

\section{Materials and Methods}

\subsection{Data}

A retrospective review of the patient charts was undertaken in the three ART centers located in Assam, a northeastern state of India. All death cases among 5612 HIV patients registered in the three ART centers between January 2006 and November 2012 were included in the study. The causes of death have been individually confirmed by the medical officers of the ART centers following the reporting of death. The patient charts were collected from ART centers where causes of death were written, and they were entered electronically by trained staff and were edited before finalizing the dataset. Since the start of ART centers in Assam in 2005-2006, there were a total of 370 deaths recorded over a period of 6 years. The causes of death were classified by using International Classification of Diseases (ICD-10) that includes a single or a combination of causes of death. Further, they were categorized into three major domains as follow:

Wasting syndrome: It is diagnosed in HIV-infected people who have unintentionally lost more than $10 \%$ of their body weight and can occur as a result of HIV infection itself but also is commonly associated with HIVrelated opportunistic infections and cancers.

AIDS related complex: It is a complex of signs and symptoms representing a less severe stage of human immunodeficiency virus (HIV) infection, characterized by chronic generalized lymphadenopathy, fever, weight loss, prolonged diarrhea, minor opportunistic infections, cytopenia, and T-cell abnormalities of the kind associated with AIDS.

Other specified condition: It includes combination of signs and symptoms like diarrhea, vomiting, fever, bleeding etc. which have been assigned as the causes of death. 


\subsection{Measures}

Along with causes of death among ART patients, other information were also obtained from patient charts included: socio-demographic characteristics, alcohol use (regular, not regular, never and past alcoholic), clinical characteristics such as CD4 count at diagnosis and prior to death (<50, $50-199,200-349$ and 350+), WHO clinical stage at the start of ART (stage1, statge2, stage3 and stage4), presence of other opportunistic infections (OIs) and ART adherence during follow-up ( $>95 \%$ and $<=95 \%)$. The socio-demographic characteristics included in this study are sex (male and female); age ( $<18$ years, 18 - 24 years, 25 - 34 years, 35 - 44 years and $45+$ years); education (illiterate, primary, secondary and college and above); occupation (unskilled/agricultural labor, service, business/self-employed and unemployed).

\subsection{Ethical Considerations}

The Assam State AIDS Control Society (ASACS) under the guidance of NACO has provided general oversight and approval for the collection and use of program data for examining the causes of death among ART patients. Patients are informed (as per the guidelines of national ART program in India) at the time of enrollment to ART centers that their medical history may be used for program strengthening. Verbal consent was taken from each patient at the time of enrollment who had agreed to use of their medical history for research purpose. All the patients were explained about the harms and benefits of being enrolled into ART and also their schedule of visits to ART centers. The counselor at the ART center recorded all these procedures. As the data presented in the study are for the purpose of program monitoring and program beneficiaries were informed about this a priori; therefore, the study was determined to be exempted for review from an institutional review board. Strict confidentiality of all the data was maintained and no personal identifiers were included in the analysis.

\subsection{Statistical Analyses}

Univariate, bivariate and multivariate analyses were performed. Percentage distribution of the causes of death was analyzed and death per 100 person years was calculated for the major causes of death. Further the sociodemographic and the clinical characteristics of the death cases were analyzed for the causes of death. To calculate proportions, Chi-square statistics were used and a p-value less than 0.05 were considered statistically significant. The survival time was measured as duration between the date of ART initiation to the reported date of death for patients who died or the date of the last recorded visit for patients who were censored (either alive till the end of the study period or lost to follow-up). Further median duration of survival from initiation of treatment was calculated based on population sub-groups of CD4 count and OIs during treatment. All statistical analyses were performed using SPSS software (version 16.0) [15].

\section{Results}

A total of 370 deaths occurred out of the total 5612 HIV patients who were registered in the three ART centers between January 2006 and November 2012. Among the 370 deaths, Tuberculosis (28\%) was the leading cause of death followed by deaths due to AIDS related complex (11\%), multiple infections and wasting syndrome (9\% each) (Table $1 \&$ Table 2). Two-thirds of the total deaths (247/370) were due to AIDS-related causes, whereas the remaining were either due to non-AIDS related causes or cause of death was unknown (24\%). The analysis of the major causes of death by the socio-demographic characteristics (Table 3) shows that in the 18 - 34 years age group, Tuberculosis and AIDS related complex were the major causes of death where as in the $>35$ years age group, multiple infections and wasting syndrome were significant contributors along with Tuberculosis. Among males, Tuberculosis (30\%) and AIDS related complex (11\%) were the leading causes of death whereas in females, Tuberculosis (23\%) and wasting syndrome (16\%) were the major contributors. Among regular alcoholics, Tuberculosis (35\%) was the leading cause of death although for a significant proportion (46\%) of deaths, the cause was unknown. Among past-alcoholics, Tuberculosis (26\%) followed by multiple infections and wasting syndrome (18\% each) were significant contributors of death. The median CD4 count at the time of diagnosis was highest among those who died of other specified conditions (110) and lowest among those who died of multiple infections (43) whereas the median CD4 count prior to death was highest among those who died of Tuberculosis (108) and lowest among those who died of multiple infections (51). More than 95\% adherence to 
Table 1. Percentage distribution of causes of death, Assam, India, 2006-2012.

\begin{tabular}{cccc}
\hline \multicolumn{4}{c}{ Number and percent distribution HIV positive patients registered in ART } \\
\multicolumn{2}{c}{ Centers and died between January 2006 and November 2012 by ICD-10 causes of death } \\
Causes of death & Number & Percent & Death per 100 person years (LB-UB) \\
\hline Tuberculosis & 105 & 28.4 & $24.8(20.5-30.0)$ \\
Candidiasis & 4 & 1.1 & $0.9(0.4-2.5)$ \\
Multiple infections & 34 & 9.2 & $8.0(5.7-11.2)$ \\
Malignancies & 5 & 1.4 & $1.2(0.5-2.8)$ \\
Encephalopathy & 7 & 1.9 & $1.7(0.8-3.5)$ \\
Wasting syndrome & 34 & $9.0(5.7-11.2)$ \\
Other specified condition & 19 & 5.1 & $4.5(2.9-7.0)$ \\
AIDS related complex & 39 & 10.5 & $9.2(6.7-12.6)$ \\
Non-AIDS related malignancies & 3 & $0.7(0.2-2.2)$ \\
Unspecified Symptoms & 18 & 4.9 & $4.2(2.7-6.7)$ \\
Suicides \& Accidents & 6 & 1.6 & $1.4(0.6-3.2)$ \\
Organ failure & 9 & 2.4 & $2.1(1.1-4.1)$ \\
Cause not known & 87 & 23.5 & $20.5(16.6-25.3)$ \\
TOTAL & 370 & 100.0 & \\
\hline
\end{tabular}

Note: Tuberculosis, candidiasis, malignancies, multiple infections, encephalopathy, wasting syndrome, other specified conditions and AIDS related complex are all resulting from HIV disease and are AIDS related deaths; The death per 100 person years were calculated as the number of deaths divided by number of persons at risk during the period multiplied with 100; Lower Bound (LB) and Upper Bound (UB) are the lower and upper limits of 95\% Confidence Intervals (CIs).

Table 2. Trend in causes of death (\%) by year, Assam, India, 2006-2012.

\begin{tabular}{|c|c|c|c|c|c|c|c|}
\hline & 2006 & 2007 & 2008 & 2009 & 2010 & 2011 & 2012 \\
\hline Total number of deaths & 22 & 20 & 48 & 56 & 70 & 69 & 85 \\
\hline AIDS-related causes & $13(59.1 \%)$ & $15(75.0 \%)$ & $34(70.8 \%)$ & $32(57.1 \%)$ & $44(62.9 \%)$ & $48(69.6 \%)$ & $61(71.8 \%)$ \\
\hline $\begin{array}{l}\text { Non-AIDS related } \\
\text { causes }\end{array}$ & 4 (18.2\%) & 2 (10.0\%) & 5 (10.4\%) & $4(7.1 \%)$ & 9 (12.9\%) & 8 (11.6\%) & 4 (4.7\%) \\
\hline Causes unknown & $5(22.7 \%)$ & $3(15.0 \%)$ & $9(18.8 \%)$ & $20(35.7 \%)$ & $17(24.3 \%)$ & $13(18.8 \%)$ & $20(23.5 \%)$ \\
\hline \multicolumn{8}{|c|}{ Specific causes of death (Number of deaths) } \\
\hline Tuberculosis & 4 & 3 & 16 & 11 & 23 & 24 & 24 \\
\hline Candidiasis & 2 & 0 & 1 & 1 & 0 & 0 & 0 \\
\hline Multiple infections & 3 & 4 & 4 & 4 & 9 & 5 & 5 \\
\hline Malignancies & 0 & 0 & 1 & 1 & 1 & 1 & 1 \\
\hline Encephalopathy & 0 & 0 & 1 & 2 & 2 & 2 & 0 \\
\hline Wasting syndrome & 1 & 1 & 2 & 2 & 3 & 10 & 15 \\
\hline $\begin{array}{l}\text { Other specified } \\
\text { condition }\end{array}$ & 0 & 3 & 3 & 3 & 5 & 2 & 3 \\
\hline AIDS related complex & 3 & 4 & 6 & 8 & 1 & 4 & 13 \\
\hline $\begin{array}{l}\text { Non-AIDS related } \\
\text { Malignancies }\end{array}$ & 1 & 0 & 1 & 1 & 0 & 0 & 0 \\
\hline Unspecified Symptoms & 3 & 1 & 2 & 2 & 5 & 4 & 1 \\
\hline Suicides \& Accidents & 0 & 0 & 1 & 1 & 2 & 1 & 1 \\
\hline Organ failure & 0 & 1 & 1 & 0 & 2 & 3 & 2 \\
\hline Cause not known & 5 & 3 & 9 & 20 & 17 & 13 & 20 \\
\hline
\end{tabular}

Note: The non-AIDS related causes include malignancies like lung cancer, anal cancer, liver cancer and Hodgkin Lymphoma, liver diseases and multiple organ failure. 
Table 3. Background characteristics of the population by the major causes of death, Assam, India, 2006-2012.

\begin{tabular}{|c|c|c|c|c|c|c|c|c|}
\hline $\begin{array}{l}\text { Background } \\
\text { Characteristics }\end{array}$ & TВ & $\begin{array}{l}\text { Multiple } \\
\text { infections }\end{array}$ & $\begin{array}{l}\text { Wasting } \\
\text { syndrome }\end{array}$ & $\begin{array}{l}\text { Other specified } \\
\text { conditions }\end{array}$ & $\begin{array}{c}\text { AIDS } \\
\text { related } \\
\text { complex }\end{array}$ & $\begin{array}{l}\text { Cause } \\
\text { unknown }\end{array}$ & Others & p-value \\
\hline Gender (\%) & & & & & & & & 0.090 \\
\hline Male $(n=296)$ & 29.7 & 9.8 & 7.4 & 4.1 & 10.5 & 24.0 & 14.5 & \\
\hline Female $(n=74)$ & 23.3 & 6.8 & 16.4 & 9.6 & 9.6 & 21.9 & 12.3 & \\
\hline Age group \% & & & & & & & & 0.067 \\
\hline$<18(\mathrm{n}=10)$ & 30.0 & 0.0 & 0.0 & 10.0 & 40.0 & 10.0 & 10.0 & \\
\hline $18-24(n=18)$ & 22.2 & 5.6 & 11.1 & 0.0 & 16.7 & 16.7 & 27.8 & \\
\hline $25-34(n=113)$ & 37.2 & 5.3 & 6.2 & 5.3 & 11.5 & 24.8 & 9.7 & \\
\hline 35 - 44 (143) & 26.6 & 12.6 & 9.1 & 6.3 & 9.8 & 23.1 & 12.6 & \\
\hline $45+(n=86)$ & 20.9 & 10.5 & 14.0 & 3.5 & 5.8 & 25.6 & 19.8 & \\
\hline Education (\%) & & & & & & & & 0.095 \\
\hline Illiterate $(\mathrm{n}=44)$ & 18.2 & 4.5 & 11.4 & 9.1 & 13.6 & 27.3 & 15.9 & \\
\hline Primary $(\mathrm{n}=92)$ & 33.7 & 9.8 & 4.3 & 3.3 & 6.5 & 32.6 & 9.8 & \\
\hline Secondary $(n=183)$ & 25.7 & 8.7 & 12.6 & 6.0 & 12.0 & 18.6 & 16.4 & \\
\hline College $\&$ above $(n=51)$ & 37.3 & 13.7 & 3.9 & 2.0 & 9.8 & 21.6 & 11.8 & \\
\hline Occupation (\%) $)^{\#}$ & & & & & & & & 0.117 \\
\hline Unskilled/agricultural labor $(n=26)$ & 11.5 & 7.7 & 15.4 & 11.5 & 11.5 & 26.9 & 15.4 & \\
\hline Service $(n=163)$ & 30.1 & 11.7 & 8.0 & 5.5 & 8.0 & 22.7 & 14.1 & \\
\hline Business/self-Employment $(\mathrm{n}=91)$ & 35.2 & 7.7 & 4.4 & 2.2 & 7.7 & 28.6 & 14.3 & \\
\hline Unemployed $(\mathrm{n}=90)$ & 23.3 & 6.7 & 14.4 & 5.6 & 17.8 & 18.9 & 13.3 & \\
\hline Use of alcohol (\%) & & & & & & & & $<0.001$ \\
\hline Regular (daily) $(\mathrm{n}=84)$ & 34.5 & 4.8 & 2.4 & 1.2 & 2.4 & 46.4 & 8.3 & \\
\hline Not regular $(\mathrm{n}=69)$ & 26.1 & 7.2 & 10.1 & 7.2 & 20.3 & 13.0 & 15.9 & \\
\hline Never $(n=179)$ & 26.8 & 10.1 & 10.1 & 6.1 & 10.6 & 21.8 & 14.5 & \\
\hline Past alcoholic $(n=38)$ & 26.3 & 18.4 & 18.4 & 5.3 & 10.5 & 0.0 & 21.1 & \\
\hline $\begin{array}{l}\text { Median CD4 count at the time of } \\
\text { diagnosis }(\mathrm{N}=370)\end{array}$ & 87 & 42.5 & 60.5 & 110 & 66 & 87 & 84 & \\
\hline $\begin{array}{l}\text { Median CD4 count prior to death } \\
\qquad(\mathrm{N}=295)\end{array}$ & 108 & 51 & 69 & 90 & 68 & 99 & 135 & \\
\hline $\begin{array}{l}\text { Adherence to ART >95\% (\%) } \\
\qquad(\mathrm{N}=314)\end{array}$ & 23.1 & 12.1 & 12.1 & 6.6 & 13.2 & 15.4 & 17.6 & \\
\hline $\begin{array}{l}\text { \% who had multiple OIs } \\
\qquad(\mathrm{N}=54)\end{array}$ & 22.2 & 22.2 & 7.4 & 7.4 & 7.4 & 20.4 & 13.0 & \\
\hline
\end{tabular}

\#Note: 1) Unskilled/agricultural laborer also includes non-agricultural laborer, domestic servant and hotel staff. 2) Service includes skilled and semiskilled worker and people in uniform. 3) Business/self-employed includes small \& large business, truck driver and local transport workers. 4) Unemployed includes housewife, students and retired people.

ART was highest among Tuberculosis deaths (23\%) and lowest among those who died of other specified conditions (7\%). The percentage of having multiple OIs was high among those who died of Tuberculosis (22\%), multiple infections (22\%) and among those where cause of death is unknown (20\%). We found a strong relationship between the patient's use of alcohol prior to death and different causes of death (Table 3). For example, among person with daily alcohol use, a greater proportion of deaths were caused by Tuberculosis (35\%) as compared to persons with occasional or no alcohol use $(26 \%)(\mathrm{p}<0.001)$.

Further analysis of the clinical and laboratory characteristics of the death cases (Table 4) shows that almost half of the deaths due to multiple infections (56\%), wasting syndrome (49\%) and AIDS related complex (45\%) had CD4 count $<50$ at the time of diagnosis. Also, across all causes of death majority of the cases had CD4 count $<200$ at the time of diagnosis. Nearly three-fifths of Tuberculosis deaths (59\%) were in WHO clinical stage 4 at the start of ART. Also, across all causes of death, majority of the cases were in WHO clinical stage 3 and 4 at the start of ART. However, significant proportion of cases whose cause of death was wasting syndrome (54\%), AIDS related complex (36\%) and other causes (46\%) were in WHO clinical stage 1 and 2 at the start of 
Table 4. Distribution of causes of death by CD4 count, WHO clinical stage, presence of OIs and adherence to ART, Assam, India, 2006-2012.

\begin{tabular}{|c|c|c|c|c|c|}
\hline \multirow[b]{2}{*}{ Major causes of death (\%) } & \multicolumn{5}{|c|}{ CD4 count at the time of diagnosis } \\
\hline & $<50$ & $50-199$ & $200-349$ & $350+$ & \multirow[t]{2}{*}{ p-value } \\
\hline Tuberculosis $(\mathrm{n}=102)$ & 24.5 & 66.7 & 8.8 & 0.0 & \\
\hline Multiple infections $(\mathrm{n}=34)$ & 55.9 & 32.4 & 8.8 & \multicolumn{2}{|l|}{2.9} \\
\hline Wasting syndrome $(\mathrm{n}=33)$ & 48.5 & 36.4 & 15.2 & \multicolumn{2}{|l|}{0.0} \\
\hline $\begin{array}{l}\text { Other specified conditions } \\
\qquad(\mathrm{n}=19)\end{array}$ & 31.6 & 36.8 & 31.6 & 0.0 & \multirow[t]{4}{*}{.005} \\
\hline AIDS related complex $(n=38)$ & 44.7 & 50.0 & 5.3 & 0.0 & \\
\hline Cause unknown $(\mathrm{n}=84)$ & 33.3 & 52.4 & 10.7 & 3.6 & \\
\hline \multirow{2}{*}{ Others $(\mathrm{n}=51)$} & 27.5 & 52.9 & 15.7 & 3.9 & \\
\hline & \multicolumn{5}{|c|}{ WHO clinical stage at the start of ART } \\
\hline Major causes of death (\%) & Stage 1 & Stage 2 & Stage 3 & Stage 4 & $\mathrm{p}$-value \\
\hline Tuberculosis $(\mathrm{n}=105)$ & 2.9 & 2.9 & 34.9 & 59.3 & \\
\hline Multiple infections $(\mathrm{n}=34)$ & 16.1 & 9.6 & 35.5 & 38.8 & \\
\hline Wasting syndrome $(\mathrm{n}=34)$ & 39.3 & 15.1 & 33.4 & 12.2 & \\
\hline $\begin{array}{l}\text { Other specified conditions } \\
\qquad(\mathrm{n}=19)\end{array}$ & 22.2 & 5.6 & 55.6 & 16.6 & .000 \\
\hline AIDS related complex $(n=39)$ & 25.0 & 11.1 & 36.2 & 27.7 & \\
\hline Cause unknown $(\mathrm{n}=87)$ & 11.7 & 7.1 & 31.7 & 49.5 & \\
\hline Others $(\mathrm{n}=52)$ & 24.0 & 22.0 & 36.0 & 18.0 & \\
\hline & & Pres & OIs during treat & & \\
\hline Major causes of death (\%) & Tuberculosis & Candidiasis & Multiple OIs & Others* & $\mathrm{p}$-value \\
\hline Tuberculosis $(\mathrm{n}=105)$ & 81.9 & 3.8 & 11.4 & 2.9 & \\
\hline Multiple infections $(\mathrm{n}=34)$ & 11.8 & 23.5 & 35.3 & 29.4 & \\
\hline Wasting syndrome $(\mathrm{n}=34)$ & 14.7 & 29.4 & 11.8 & 44.1 & \\
\hline $\begin{array}{l}\text { Other specified conditions } \\
\qquad(\mathrm{n}=19)\end{array}$ & 36.8 & 15.8 & 21.1 & 26.3 & .000 \\
\hline AIDS related complex $(n=39)$ & 17.9 & 33.3 & 10.3 & 38.5 & \\
\hline Cause unknown $(\mathrm{n}=87)$ & 34.5 & 20.7 & 12.6 & 32.2 & \\
\hline Others $(n=52)$ & 13.5 & 26.9 & 13.5 & 46.2 & \\
\hline & & ART a & e during last fol & & \\
\hline Major causes of death (\%) & Adhe & $95 \%$ & Adhe & $95 \%$ & $\mathrm{p}$-value \\
\hline Tuberculosis $(\mathrm{n}=84)$ & & & & & \\
\hline Multiple infections $(\mathrm{n}=32)$ & & & & & \\
\hline Wasting syndrome $(\mathrm{n}=34)$ & & & & & \\
\hline $\begin{array}{l}\text { Other specified conditions } \\
\qquad(\mathrm{n}=19)\end{array}$ & & & & & .000 \\
\hline AIDS related complex $(n=38)$ & & & & & \\
\hline Cause unknown $(\mathrm{n}=57)$ & & & & & \\
\hline Others $(n=50)$ & & & & & \\
\hline
\end{tabular}

Note: * Other OIs includes prolong fever, prolong diarrhea, Respiratory tract infections, Hepatitis virus infection, Herpes infections and carcinomas. 
ART. Among deaths due to Tuberculosis, Tuberculosis (82\%) was the major OI during treatment. Tuberculosis was also the major OI among $37 \%$ deaths due to other specified conditions and $35 \%$ deaths where the cause of death is unknown. For deaths due to wasting syndrome, other OIs (44\%) (e.g. prolong fever, prolong diarrhea, respiratory tract infections, hepatitis virus infection, herpes infections and carcinomas) was the major OI during treatment. WHO clinical stage at the start of treatment was significantly associated with causes of death ( $\mathrm{p}<$ 0.001) (Table 4). Among deaths due to Tuberculosis, 59\% were in WHO clinical stage 4 at the start of treatment. Similarly, among deaths due to multiple infections, 39\% were in WHO clinical stage 4 at the start of treatment. There was also significant association between the major OIs during treatment and the causes of death ( $<$ $0.001)$.

Year wise analysis of the causes of death showed that Tuberculosis (30\%) was the major cause of death among ART patients each year. It was also seen that deaths due to wasting syndrome and AIDS-related complex had increased in the last three years while there was a declining trend among deaths due multiple infections (Figure 1). Median duration of survival from treatment initiation to death was calculated based on CD4 at the beginning of ART and major OIs during treatment. The median survival results (Figure 2) suggest that survival duration of patients was inversely proportional to the CD4 count at the initiation of ART. Among patients with OIs during treatment, the longest survival period was among patients with other OIs (5.0 months) and lowest among those who had multiple OIs (2.5 months).

\section{Discussion}

The findings of this study indicates that Tuberculosis, AIDS related complex, multiple infections and wasting

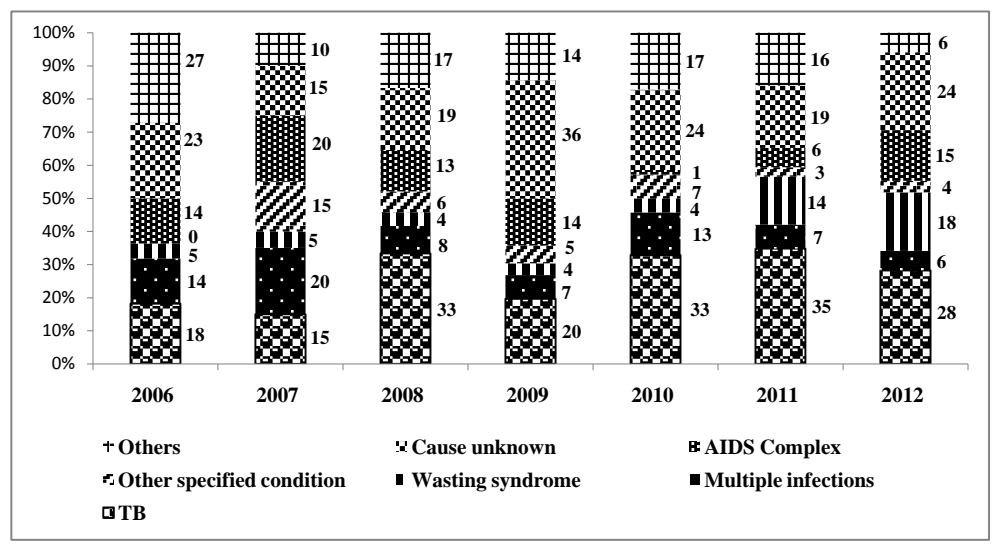

Figure 1. Year wise distribution of causes of death, Assam, India, 2006-2012.

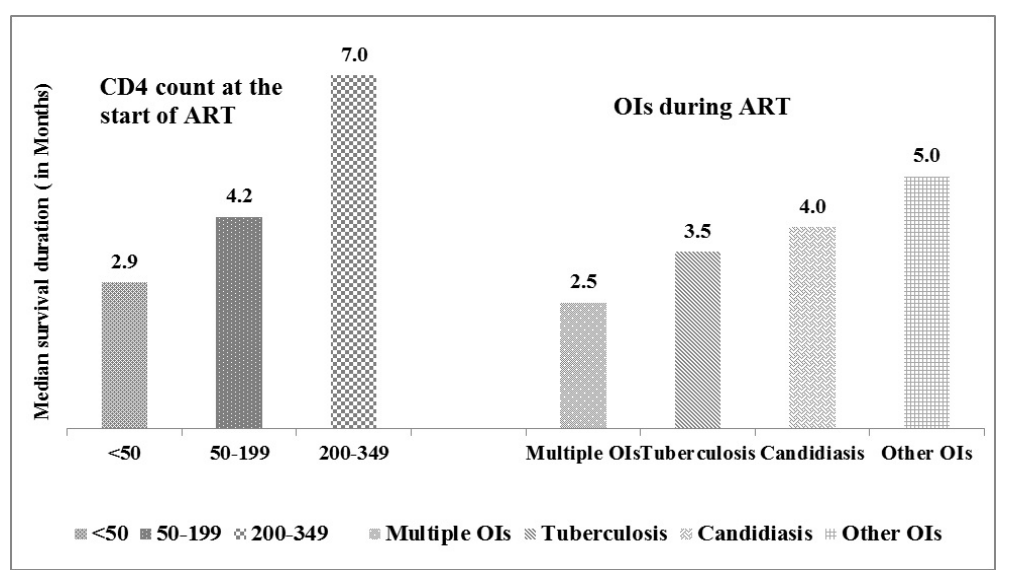

Figure 2. Median survival duration (in months) among HIV infected individuals by CD4 count at the start of ART and OIs during ART, Assam, India, 2006-2012. 
syndrome were the leading causes of death among HIV-infected patients in northeastern India. Tuberculosis has emerged as a leading cause of death among HIV-infected patients. Similar findings were noted in other studies in India and elsewhere [4] [16] [17]. The findings of the study add further that the high proportion of deaths due to multiple infections and wasting syndrome is a growing concern. Although majority of deaths have occurred due to AIDS and non-AIDS related causes, a considerable proportion of deaths were also reported where causes are unknown; a finding similar to the previous studies [2] [18]. The proportion of deaths due to unknown causes (24\%) in this study is much higher compared to the other studies [19] [20]. It may be due to the causes of death were assigned as reported by the health staff or relatives. However, the deaths due to unknown causes may be also attributable to Tuberculosis as there is similarity in the predictor variables for both the causes (e.g. Use of alcohol, median CD4 count and having multiple infections).

This study highlights that the deaths due to different causes are significantly associated with patient's use of alcohol, WHO clinical stage, CD4 count at the time of diagnosis, presence of opportunistic infections during treatment and ART adherence. The study findings illustrate that majority of patients who died with multiple infections which is suggestive of advance AIDS had CD4 count $<200$ cells $/ \mu \mathrm{L}$ at HIV diagnosis. This finding is consistent with a recent study which highlighted that CD4 at baseline continues to play an important role in predicting deaths due to AIDS [21]. The study describes that 59\% of Tuberculosis related AIDS deaths were in WHO Clinical stage 4 at ART initiation, a finding similar to another study which shows WHO clinical stage 4 as an important risk factor for Tuberculosis mortality among HIV infected individuals [22]. The study shows that 82\% of the AIDS deaths due to Tuberculosis had Tuberculosis as the major OI during ART while $35 \%$ multiple infections related AIDS deaths had multiple OIs during ART.

The study shows a significant association between regular use of alcohol and deaths due to Tuberculosis. Various studies done across the world and India have also shown that use of alcohol increases the risk of Tuberculosis [23] [24]. In addition, both alcohol consumption and HIV infection impairs the host's defense mechanism against Tuberculosis infection and disease [25] [26]. Further, alcohol consumption also affects the adherence to HIV and Tuberculosis treatment. The study indicates that more than half of deaths due to multiple infections (56\%) had CD4 count less than 50 at the time of diagnosis which highlights the fact that they have undergone HIV testing at the last stage and had already developed AIDS, a similar finding was noted in other settings [27] [28]. The study also confirms wasting syndrome (9\%) as a major cause of mortality. Similar findings have been documented in a study done in Uganda where more than $30 \%$ of deaths had occurred due to wasting syndrome [29]. The study findings urge for further research to explore the underlying causes for AIDSrelated mortality due to wasting syndrome in India. The study findings should be interpreted cautiously in light of certain study limitations. First, the causes of death were not based on proper death certificate but as reported by family members and relatives, and assigned by the health officials in ART centers. Second, as this study only included death cases, survival analysis could not be done and only survival duration was calculated. Third, the analysis is limited to the variables that were available in the recorded data. Further research could examine the range of factors associated with causes of death among HIV positive population.

\section{Conclusion}

The study demonstrates that AIDS-related causes continue to be the leading causes of deaths among HIV patients in north-eastern India. Among them, Tuberculosis is the leading cause of death. The study also stressed on the fact that there was a need for further research into other causes of death, i.e., due to AIDS-related complex and wasting syndrome. This highlights the need for further strengthening the referral and linkages in the HIVTuberculosis program. In addition, counseling services at the HIV and Tuberculosis care settings should also address the issue of alcohol use by providing appropriate counseling to the patients. The study findings have also important policy implications for ART programs in India. Efforts are required at the management as well as at implementation level for constant and regular follow-up with all HIV patients. Further, this is essential to increase the risk perception as well as to the knowledge about the benefits of ART among these individuals which can increase the adherence level and survival rate. In addition, the program should expand the provision of ART services to more remote areas to provide services to some of the underserved population groups like women and other key population. Proper strategies are required to ensure early diagnosis and enrollment into ART for patients with very low CD4 count. Furthermore, community level sensitization is required to reduce stigma and discrimination towards HIV positive individuals so that patients can access treatment without any hesitation. In 
addition to that this study strongly recommends further research and advocacy to ensure that disease specific interventions are appropriately addressed in HIV programs and policies.

\section{Acknowledgements}

This paper was written as part of the Knowledge Network Project (KNP) of the Population Council, which is a grantee of the Bill \& Melinda Gates Foundation through Avahan - the India AIDS Initiative. The views expressed herein are those of the authors and do not necessarily reflect the official policy or position of the Bill \& Melinda Gates Foundation and Avahan. We wish to acknowledge the contributions made by Dr. Indrani Dey, Dr. Biswadeep Borthakur and Dr. Rajeev Dey, the medical officers at ART centers in Assam, who helped in assigning the causes of death. We are grateful to other colleagues of ASACS, NACO and Population Council for providing the necessary inputs for writing this paper. We appreciate the reviewers for their valuable suggestions that have improved the presentation of the paper.

\section{Conflict of Interest and Funding}

There is no conflict of interest in the present study for any of the authors.

\section{References}

[1] Palella, F.J., Delaney, K.M., Moorman, A.C., et al. (1998) Declining Morbidity and Mortality among Patients with Advanced Human Immunodeficiency Virus Infection. New England Journal of Medicine, 338, 853-860. http://dx.doi.org/10.1056/NEJM199803263381301

[2] Krentz, H., Kliewer, G. and Gill, M. (2005) Changing Mortality Rates and Causes of Death for HIV-Infected Individuals Living in Southern Alberta, Canada from 1984 to 2003. HIV Medicine, 6, 99-106. http://dx.doi.org/10.1111/j.1468-1293.2005.00271.x

[3] Palella, F.J., Baker, R.K., Moorman, A.C., et al. (2006) Mortality in the Highly Active Antiretroviral Therapy Era: Changing Causes of Death and Disease in the HIV Outpatient Study. Journal of Acquired Immune Deficiency Syndromes, 43, 27-34. http://dx.doi.org/10.1097/01.qai.0000233310.90484.16

[4] Cain, K.P., Anekthananon, T., Burapat, C., et al. (2009) Causes of Death in HIV-Infected Persons Who Have Tuberculosis, Thailand. Emerging Infectious Diseases, 15, 258-264. http://dx.doi.org/10.3201/eid1502.080942

[5] Bachani, D., Garg, R., Rewari, B.B., Hegg, L., Rajasekaran, S., et al. (2010) Two-Year Treatment Outcomes of Patients Enrolled in India’s National First-Line Antiretroviral Therapy Programme. National Medical Journal of India, 23, 7-12.

[6] National AIDS Control Organization (2012) Technical Report India HIV Estimates. New Delhi.

[7] Kumarasamy, N., Solomon, S., Chaguturu, S.K., Cecelia, A.J., Vallabhaneni, S., Flanigan, T.P., et al. (2005) The Changing Natural History of HIV Disease: Before and After the Introduction of Generic Antiretroviral Therapy in Southern India. Clinical Infectious Diseases, 41, 1525-1528. http://dx.doi.org/10.1086/497267

[8] Teja, V.D., Sudha, T. and Lakshmi, V. (2007) Causes and Pattern of Mortality in HIV-Infected, Hospitalized Patients in a Tertiary Care Hospital: A Fourteen Year Study. Indian Journal of Medical Sciences, 61, 555-561. http://dx.doi.org/10.4103/0019-5359.35805

[9] Ghate, M., Deshpande, S., Tripathy, S., Nene, M., Gedam, P., Godbole, S., et al. (2009) Incidence of Common Opportunistic Infections in HIV-Infected Individuals in Pune, India: Analysis by Stages of Immunosuppression Represented by CD4 Counts. International Journal of Infectious Diseases, 13, e1-e8. http://dx.doi.org/10.1016/j.ijid.2008.03.029

[10] Chakraborty, N., Mukherjee, A., Santra, S., Sarkar, R.N., Banerjee, D., Guha, S.K., Chakraborty, S. and Bhattacharyya, S.K. (2008) Current Trends of Opportunistic Infections among HIV-Seropositive Patients from Eastern India. Japanese Journal of Infectious Diseases, 61, 49-53.

[11] Venkatesh, K.K., Saghayam, S., Devaleenal, B., Poongulali, S., Flanigan, T.P., Mayer, K.H. and Kumarasamy, N. (2012) Spectrum of Malignancies among HIV-Infected Patients in South India. Indian Journal of Cancer, 49, 176-180. http://dx.doi.org/10.4103/0019-509X.98947

[12] Aggarwal, P., Sharma, A., Bhardwaj, R. and Raina, R. (2009) Myocardial Dysfunction in Human Immunodeficiency Virus Infection: An Echocardiographic Study. The Journal of the Association of Physicians of India, 57, 745-746.

[13] Stewart, A., Carusone, S.C., To, K., McDaniel, N.S., Halman, M. and Grimes, R. (2012) Causes of Death in HIV Patients and the Evolution of an AIDS Hospice: 1988-2008. AIDS Research and Treatment, 2012, 1-7. http://dx.doi.org/10.1155/2012/390406

[14] Rupali, P., Mannam, S., Bella, A., John, L., Rajkumar, S., Clarence, P., et al. (2012) Risk Factors for Mortality in a 
South Indian Population on Generic Antiretroviral Therapy. Journal of the Association of Physicians of India, 60, 1114.

[15] University of Bristol (2010) Introduction to SPSS (Version 16) for Windows: Practical Work Book. University of Bristol Information Services, USA, March, 2010.

[16] Rajagopalan, N., Suchitra, J.B., Shet, A., Khan, Z.K., Martin, G.J., Nonnemacher, M.R., et al. (2009) Mortality among HIV-Infected Patients in Resource Limited Settings: A Case-Controlled Analysis of Inpatients in a Community Care Centre. American Journal of Infectious Diseases, 5, 219-224. http://dx.doi.org/10.3844/ajidsp.2009.219.224

[17] Hosegood, V., Vanneste, A.M. and Timaeus, I.M. (2004) Levels and Causes of Adult Mortality in Rural South Africa: The Impact of AIDS. AIDS, 18, 663-671. http://dx.doi.org/10.1097/00002030-200403050-00011

[18] Pacheco, A.G., Tuboi, S.H., May, S.B., Moreira, L.F.S., Ramadas, L., Nunes, E.P., et al. (2009) Temporal Changes in Causes of Death among HIV-Infected Patients in the HAART Era in Rio De Janeiro, Brazil. Journal of Acquired Immune Deficiency Syndromes, 51, 624-630. http://dx.doi.org/10.1097/QAI.0b013e3181a4ecf5

[19] Lewden, C., Salmon, D., Morlat, P., Bevilacqua, S., Jougla, E., Bonnet, F., et al. (2005) Causes of Death among Human Immunodeficiency Virus (HIV)-Infected Adults in the Era of Potent Antiretroviral Therapy: Emerging Role of Hepatitis and Cancers, Persistent Role of AIDS. International Journal of Epidemiology, 34, 121-130. http://dx.doi.org/10.1093/ije/dyh307

[20] Jain, M.K., Skiest, D.J., Cloud, J.W., Jain, C.L., Burns, D. and Berggren, R.E. (2003) Changes in Mortality Related to Human Immunodeficiency Virus Infection: Comparative Analysis of Inpatient Deaths in 1995 and in 1999-2000. Clinical Infectious Diseases, 36, 1030-1038. http://dx.doi.org/10.1086/368186

[21] Ingle, L.M., May, M.T., Gill, M.J., Mugavero, M.J., Lewden, C., Abgrali, S., et al. (2014) Impact of Risk Factors for Specific Causes of Death in the First and Subsequent Years of Antiretroviral Therapy among HIV-Infected Patients. Clinical Infectious Diseases, 59, 287-297. http://dx.doi.org/10.1093/cid/ciu261

[22] Kassa, A., Teka, A., Shewaamare, A. and Jerene, D. (2012) Incidence of Tuberculosis and Early Mortality in a Large Cohort of HIV Infected Patients Receiving Antiretroviral Therapy in a Tertiary Hospital in Addis Ababa, Ethiopia. Transactions of the Royal Society of Tropical Medicine and Hygiene, 106, 363-370. http://dx.doi.org/10.1016/j.trstmh.2012.03.002

[23] Gajalakshmi, V. and Peto, R. (2009) Smoking, Drinking and Incident Tuberculosis in Rural India: Population-Based Case-Control Study. International Journal of Epidemiology, 38, 1018-1025. http://dx.doi.org/10.1093/ije/dyp225

[24] Jürgen, R., Andriy, V.S., Manuela, G.N., Robin, R., Charles, P., Knut, L., Patra, J., Poznyak, V. and Popova, S. (2009) The Association between Alcohol Use, Alcohol Use Disorders and Tuberculosis (TB). A Systematic Review. BMC Public Health, 9, 450. http://dx.doi.org/10.1186/1471-2458-9-450

[25] O’Connell, R., Chishinga, N., Kinyanda, E., Patel, V., Ayles, H., Weiss, H.A. and Seedat, S. (2013) Prevalence and Correlates of Alcohol Dependence Disorder among TB and HIV Infected Patients in Zambia. PLoS ONE, 8, e74406. http://dx.doi.org/10.1371/journal.pone.0074406

[26] Lonnroth, K., Jaramillo, E., Williams, B.G., Dye, C. and Raviglione, M. (2009) Drivers of Tuberculosis Epidemics: The Role of Risk Factors and Social Determinants. Social Science \& Medicine, 68, 2240-2246. http://dx.doi.org/10.1016/j.socscimed.2009.03.041

[27] Jensen, F.S., Pedersen, L., Pedersen, C., Larsen, C.S., Tauris, P., Møller, A., Sørensen, H.T. and Obel, N. (2004) Low Mortality in HIV-Infected Patients Starting Highly Active Antiretroviral Therapy: A Comparison with the General Population. AIDS, 18, 89-97. http://dx.doi.org/10.1097/00002030-200401020-00011

[28] Egger, M., May, M., Chêne, G., Phillips, A.N., Ledergerber, B., Dabis, F., Costagliola, D., D’Arminio, M.A., De, W.F., Reiss, P., Lundgren, J.D., Justice, A.C., et al. (2002) ART Cohort Collaboration. Prognosis of HIV-1-Infected Patients Starting Highly Active Antiretroviral Therapy: A Collaborative Analysis of Prospective Studies. The Lancet, 13, 119129. http://dx.doi.org/10.1016/S0140-6736(02)09411-4

[29] Okongo, M., Morgan, D., Mayanja, B., Ross, A. and Whitworth, J. (1998) Causes of Death in a Rural, PopulationBased Human Immunodeficiency Virus Type 1 (HIV-1) Natural History Cohort in Uganda. International Journal of Epidemiology, 27, 698-702. 